Published in Comparative Biochemistry and Physiology Part D 6 (2011) 224-234.

\title{
Comparative Studies of Vertebrate Lipoprotein Lipase: A Key Enzyme of Very Low Density Lipoprotein Metabolism
}

\author{
Roger S Holmes ${ }^{1-4}$, John L Vandeberg ${ }^{1,2}$ and Laura A Cox ${ }^{1,2}$ \\ ${ }^{1}$ Department of Genetics and ${ }^{2}$ Southwest National Primate Research Center, Southwest Foundation for \\ Biomedical Research, San Antonio, TX, USA, and ${ }^{3}$ School of Biomolecular and Physical Sciences, Griffith \\ University, Nathan, QLD, Australia
}

\author{
${ }^{4}$ Corresponding Author: \\ Roger S Holmes, D.Sc. \\ Department of Genetics \\ Southwest National Primate Research Center \\ Southwest Foundation for Biomedical Research \\ San Antonio, TX, USA 78227 \\ Email: rholmes@sfbrgenetics.org
}

Phone: $210-258-9687$

Fax: $210-258-9600$

Keywords: Vertebrates; amino acid sequence; lipoprotein lipase; evolution; gene duplication.

Running Head: Vertebrate lipoprotein lipase: comparative studies and evolution

\section{Summary}

Lipoprotein lipase (LIPL or LPL; E.C.3.1.1.34) serves a dual function as a triglyceride lipase of circulating chylomicrons and very-low-density lipoproteins (VLDL) and facilitates receptor-mediated lipoprotein uptake into heart, muscle and adipose tissue. Comparative LIPL amino acid sequences and protein structures and LIPL gene locations were examined using data from several vertebrate genome projects. Mammalian LIPL genes usually contained 9 coding exons on the positive strand. Vertebrate LIPL sequences shared $58-99 \%$ identity as compared with 33-49\% sequence identities with other vascular triglyceride lipases, hepatic lipase (LIPC) and endothelial lipase (LIPE). Two human LIPL N-glycosylation sites were conserved among seven predicted sites for the vertebrate LIPL sequences examined. Sequence alignments, key amino acid residues and conserved predicted secondary and tertiary structures were also studied. Potential sites for regulating LIPL gene expression identified were a $\mathrm{CpG}$ island within the 5'untranslated region; transcription factor binding sites in the 5' flanking region and the 5'-untranslated region of the human LIPL gene; and a microRNA binding site within the 3'- 
untranslated region of the human $L I P L$ gene. Phylogenetic analyses examined the relationships and potential evolutionary origins of vertebrate lipase genes, $L I P L, L I P G$ and $L I P C$ which suggested that these have been dreived from gene duplication events of an ancestral neutral lipase gene, prior to the appearance of fish during vertebrate evolution $>500$ million years ago. Comparative divergence rates for these vertebrate sequences indicated that $L I P L$ is evolving more slowly (2-3 times) than for $L I P C$ and $L I P G$ genes and proteins.

\section{Introduction}

Lipoprotein lipase (LIPL or LPL; E.C.3.1.1.34) is one of three members of the triglyceride lipase family that contributes to vascular lipoprotein degradation and plays major roles in hydrolyzing circulating chylomicrons and very-low-density lipoproteins (VLDL) and in facilitating receptor-mediated lipoprotein uptake into heart, muscle and adipose tissue of the body (Wion et al., 1987; Dichek et al., 1991; Benlian et al., 1996). Hepatic lipase (LIPC; E.C. 3.1.1.3) also serves a dual role in triglyceride hydrolysis and in ligandbinding for receptor-mediated lipoprotein uptake into the liver (Martin et al., 1988; Datta et al., 1988; Cai et al., 1989) whereas endothelial lipase (LIPE; E.C.3.1.1.3) functions in high density lipoprotein (HDL) hydrolysis in the body (Jaye et al., 1999; Hirata et al., 1999). These enzymes are members of the vascular lipase gene family which have significant sequence similarities (Hirata et al., 1999; Ma et al., 2003; Brown \& Rader, 2007).

The gene encoding LIPL ( $L I P L$ or $L P L)$ is expressed in various cells and tissues of the body, including heart, muscle, adipose tissue, brain, macrophages, lung, lactating mammary gland and endothelial cells where the enzyme hydrolyzes triglycerides from chylomicrons and very-low-density lipoproteins (VLDL) (Wion et al., 1987; Dichek et al., 1991; Benlian et al., 1996; Su et al., 2004). Studies of $\mathrm{Lipl}^{-} / \mathrm{Lipl}^{-}$knock out mice have shown that LIPL-deficiency causes severe hypertriglyceridemia, reduced high-density lipoprotein (HDL) levels and death within 18 hours of birth (Weinstock et al., 1995). Human clinical studies have also examined loss of function $L I P L$ mutations leading to familial chylomicronemia or hyperlipoproteinemia type I, a rare recessive disorder appearing in children and characterized by dramatically reduced HDL-cholesterol ratios and very high blood triglyceride levels (Amies et al., 1991; Faustinella et al., 1991; Mead et al., 2002). In addition, human LIPL polymorphisms influence significantly a number of major diseases, including atherosclerosis (Reymer et al., 1995; Shimo-Nakanishi et al., 2001; Tsutsumi, 2003), atherosclerotic cerebral infarction (Xu et al., 2008), ischemic stroke (Zhao et al., 2003), coronary artery disease (Zhang et al., 1998; Spence et al., 2003), preeclampsia (Hubel et al., 1999; Zhang et al., 2006), Alzheimer's disease (Papassotiropoulos et al., 2005; Blain et al., 2006), ulcerative colitis (Kosaka et al., 2006), hypertension (Chen et al., 2005), diabetes (Ukkola et al., 2005) and obesity (Huang et al., 2006; Radha et al., 2007). 
Structures of several vertebrate LIPL genes have been determined, including human (Wion et al., 1987; Chuat et al., 1992), mouse (Zechner et al., 1991), rat (Brault et al., 1992; The MGC Project Team, 2004) and chicken (Cooper et al., 1992). Several LIPL cDNA and amino acid sequences have also been reported for other vertebrates including gorilla (Gorilla gorilla) and rhesus monkey (Macaca mulatta) (Martinez et al., 2001), baboon (Papio anubis) (Cole \& Hixson, 1995), pig (Sus scrofa) (Harbitz et al., 1991), cow (Bos taurus) (Senda et al., 1987), sheep (Ovis aries) (Edwards et al., 1993), cat (Felis catus) (Ginzinger et al., 1996), goat (Capra hercus) (Badaoui et al., 2007) and guinea pig (Cavia porcellus) (Enerbaeck et al., 1987) and fish species, sea bass (Dicentrarchus labrax) (Jose Ilbanez et al., 2008) and bream (Sparus aurata; Pagrus major) (Saera-Vila et al., 2005; Oku et al., 2006). LIPL genes usually contain 9 exons of DNA encoding LIPL sequences which may undergo exon shuffling generating several isoproteins in each case (Thierry-Mieg and Thierry-Mieg, 2006). Three dimensional studies of pancreatic lipase (LIPP) (Winkler et al., 1990; Bourne et al., 1994) and molecular modeling of human LPL (van Tilbeurgh et al., 1994) have enabled identification of three major structural domains for the mammalian neutral lipase family, including an N-terminal domain with a catalytic triad of serine, aspartate and histidine residues; a 'lid' domain which covers the active site and contributes to the specificity for triglyceride and phosphoglyceride substrates; and a C-terminal or 'plat' domain, which contributes to lipid binding and specificity. LIPL is synthesized by the endoplasmic reticulum (ER) of parenchymal cells and sequentially processed by the Golgi and ER with the addition of carbohydrate (Ailhaud, 1990; Stins et al., 1993; Hata et al., 1993). LIPL is also subject to proprotein convertase cleavage at a site in the 'hinge' region separating the N- and C-terminal enzyme domains (Jin et al., 2005) and behaves as a homodimer with a proposed head-to-tail conformation (Murthy et al., 1996; Wong et al., 1997; Kobayashi et al., 2002). Following secretion, LIPL binds to heparan sulfate proteoglycans on the endothelial surface by electrostatic charge effects onto the luminal surface of capillary endothelial cells and macrophages (reviewed by Tsutsumi, 2003).

This paper reports the predicted gene structures and amino acid sequences for several vertebrate $L I P L$ genes and proteins, the predicted secondary and tertiary structures for vertebrate LIPL enzymes, several potential sites for regulating human $L I P L$ gene expression and the structural, phylogenetic and evolutionary relationships for these genes and enzymes with those for human, mouse and rat lipase gene families.

\section{Methods}

\section{Vertebrate $L I P L$ gene and protein identification}


BLAST (Basic Local $\underline{\text { Alignment }}$ Search Tool) studies were undertaken using web tools from the National Center for Biotechnology Information (NCBI) (http://blast.ncbi.nlm.nih.gov/Blast.cgi) (Altschul et al, 1997). Protein BLAST analyses used vertebrate LIPL amino acid sequences previously described (Table 1). Non-redundant protein sequence databases for several mammalian genomes were examined using the blastp algorithm, including human (Homo sapiens) (International Human Genome Sequencing Consortium, 2001); chimpanzee (Pan troglodytes) (Chimpanzee Genome Analysis Consortium, 2005); orangutan (Pongo abelii) (http://genome.wustl.edu) ; cow (Bos Taurus) (Bovine Genome Project, 2008); horse (Equus caballus) (Horse Genome Project, 2008); mouse (Mus musculus) (Mouse Sequencing Consortium, 2002); rat (Rattus norvegicus) (Rat Genome Sequencing Consortium, 2004); opossum (Monodelphis domestica) (Mikkelsen et al., 2007); platypus (Ornithorhynchus anatinus) (Warren et al., 2008); frog (Xenopus tropicalis) (http://genome.jgipsf.org/Xentr3/Xentr3.home.html); stickleback (http://www.broadinstitute.org/models/stickleback )

(Gasterosteus aculeatus); and seasquirt (Ciona intestinalis) (http://genome.jgi-psf.org/ciona4/ciona4.info.html). This procedure produced multiple BLAST 'hits' for each of the protein databases which were individually examined and retained in FASTA format, and a record kept of the sequences for predicted mRNAs and encoded LIPL-like proteins . These records were derived from annotated genomic sequences using the gene prediction method: GNOMON and predicted sequences with high similarity scores for human LIPL. Predicted LIPL-like protein sequences were obtained in each case and subjected to analyses of predicted protein and gene structures.

BLAT analyses were subsequently undertaken for each of the predicted LIPL amino acid sequences using the UC Santa Cruz genome browser [http://genome.ucsc.edu/cgi-bin/hgBlat] (Kent et al. 2003) with the default settings to obtain the predicted locations for each of the mammalian $L I P L$ genes, including predicted exon boundary locations and gene sizes. BLAT analyses were similarly undertaken for other human lipase genes using previously reported sequences for encoded lipases in each case (see Table 1). Structures for human and mouse isoforms (splicing variants) were obtained using the AceView website to examine predicted gene and protein structures (Thierry-Mieg and Thierry-Mieg, 2006)

(http://www.ncbi.nlm.nih.gov/IEB/Research/Acembly/index.html?human) .

\section{Predicted Structures and Properties of Vertebrate Lipoprotein Lipases}

Predicted secondary and tertiary structures for human and other vertebrate LIPL proteins were obtained using the PSIPRED v2.5 web site tools provided by Brunel University (McGuffin et al. 2000) [http://bioinf.cs.ucl.ac.uk/psipred/psiform.html] and the SWISS MODEL web tools [http://swissmodel.expasy.org/], 
respectively (Guex \& Peitsch 1997; Kopp \& Schwede 2004). The reported tertiary structure for human pancreatic lipase related protein 1 (LIPR1) (Walker et al., 2010) served as the reference for the predicted human, opossum and frog LIPL tertiary structures, with modeling ranges of residues 36 to 450,38 to 453 and 23 to 438 respectively. Theoretical isoelectric points and molecular weights for vertebrate LIPL proteins were obtained using Expasy web tools (http://au.expasy.org/tools/pi tool.html). SignalP 3.0 web tools were used to predict the presence and location of signal peptide cleavage sites (http://www.cbs.dtu.dk/services/SignalP/) for each of the predicted vertebrate LIPL sequences (Emanuelsson et al 2007). The NetNGlyc 1.0 Server was used to predict potential N-glycosylation sites for vertebrate LIPL proteins (http://www.cbs.dtu.dk/services/NetNGlyc/).

\section{Comparative Human and Mouse Lipoprotein Lipase Gene (LIPL) Expression}

The genome browser (http://genome.ucsc.edu) (Kent et al. 2003) was used to examine GNF Expression Atlas 2 data using various expression chips for human and mouse $L I P L$ genes (http://biogps.gnf.org) (Su et al, 2004). Gene array expression 'heat maps' were examined for comparative gene expression levels among human and mouse tissues showing high (red); intermediate (black); and low (green) expression levels.

\section{Phylogeny Studies and Sequence Divergence}

Alignments of vertebrate lipoprotein lipase (LIPL), hepatic lipase (LIPC) and endothelial (LIPE) sequences were assembled using BioEdit v.5.0.1 and the default settings (Hall, 1999). Alignment ambiguous regions, including the amino and carboxyl termini, were excluded prior to phylogenetic analysis yielding alignments of 429 residues for comparisons of vertebrate LIPL sequences with human and mouse LIPC and LIPE sequences with the seasquirt (Ciona intestinalis) lipase sequence (Table 1). Evolutionary distances were calculated using the Kimura option (Kimura, 1983) in TREECON (Van de Peer \& de Wachter, 1994).

Phylogenetic trees were constructed from evolutionary distances using the neighbor-joining method (Saitou \& Nei, 1987) and rooted with the seasquirt lipase sequence. Tree topology was reexamined by the boot-strap method (100 bootstraps were applied) of resampling and only values that were highly significant $(\geq 90)$ are shown (Felsenstein, 1985).

\section{Results and Discussion}

\section{Alignments of Vertebrate Lipoprotein Lipase (LIPL) Amino Acid Sequences with Horse Pancreatic Lipase (LIPP)}

The deduced amino acid sequences for opossum (Monodelphis domestica), frog (Xenopus tropicalis) and stickleback (Gasterosteus aculeatus) LIPL are shown in Figure 1 together with previously reported sequences for 
human (Wion et al., 1987; Dichek et al., 1991), mouse (Zechner et al., 1991), rat (Brault et al., 1992), chicken LIPL (Cooper et al., 1992; Raisonnier et al., 1995) and horse pancreatic lipase (LIPP) (Bourne et al., 1994) (Table 1). Alignments of human and other vertebrate LIPL sequences examined showed between 58-99\% identities, suggesting that these are products of the same family of genes, whereas comparisons of sequence identities of vertebrate LIPL proteins with human and mouse LIPC and LIPE and horse LIPP exhibited lower levels of sequence identities: LIPC (41\% and 44\% respectively); LIPG (44\% and 45\% respectively) and LIPP (24\%), indicating that these are members of distinct lipase families (Table 2).

The amino acid sequences for mammalian and chicken LIPL contained 474-478 residues whereas frog (Xenopus tropicalis) and stickleback (Gasterosteus aculeatus) LIPL contained 466 and 514 amino acids, respectively, with the latter having extended $\mathrm{N}$ - and C-terminal sequences (Figure 1). Previous three dimensional studies of horse pancreatic lipase (LIPP) (Bourne et al., 1994) and modeling studies of human LIPL (van Tilbeurgh et al., 1994) have enabled predictions of key residues for these vertebrate LIPL proteins (sequence numbers refer to human LIPL). These included the catalytic triad for the active site (Ser159; Asp183; His266); the hydrophobic Nterminus signal peptides (see also Table 1) which facilitate enzyme secretion into the circulation system (Jin et al., 2003); disulfide bond forming residues (Cys54/Cys68; Cys243/Cys266; Cys291/Cys302; Cys305/Cys310; Cys445/Cys466) (the latter disulfide bond is apparently absent in the stickleback LIPL sequence); the predicted 'lid' region (244-265) which covers the active site and participates in lipid substrate binding in analogous lipases (Winkler et al., 1990; Bourne et al., 1994); and a predicted 'hinge' region for vertebrate LIPL, containing a proteolytic cleavage site for proprotein convertase (320Arg-321Ala-322Lys-323Arg) (Jin et al., 2003; 2005) (see Figure 2). Specific tyrosine residues predicted for nitration following lipopolysaccharide (LPS) challenging were identified (tyrosines 121, 127 and 314) which down-regulate LIPL activity and reduce triglyceride clearance from the body (Casanovas et al, 2009). These residues were conserved for all of the vertebrate LIPL sequences examined (Figure 1) possibly because of this role in reducing LIPL activity following LPS administration, resulting in 'lipemia' and increased binding of triglyceride-rich lipoproteins with LPS which undergo clearance by the liver (Gouni et al, 1993). With the exception of the N-terminus signal peptides, all of these sequences were strictly conserved or underwent conservative substitutions which may reflect the essential nature of these residues in contributing to LIPL structure and function. The N-terminal region (residues 1-32 for human LIPL) however underwent major changes in the number and sequence of amino acid residues but retained a predicted signal peptide property in each case (Fig. 1; Table 1). The horse LIPP sequence shared the catalytic triad residues, four of the five 
disulfide bonds predicted for the vertebrate LIPG sequences and an N-signal peptide sequence property however other sequences were distinct with only $25 \%$ identical residues observed for horse LIPP and human LIPL.

Heparin binding sites have been previously shown to play key roles in binding LIPL and related neutral vascular lipases, LIPC and LIPE, to heparin sulfate proteoglycans on the luminal side of endothelial cells (Hill et al., 1998; Sendak \& Bensadoun, 1998). Figure 2 summarizes the comparative amino acid sequences for vertebrate LIPL for several sites previously investigated by Beg and coworkers (1998). A nonbasic amino acid region similar to type 1 repeats of thrombospondin (TSP) (Prater et al., 1991) and four basic amino acid clusters are compared for 14 vertebrate LIPL sequences, including 2 fish species, zebrafish (Danio rerio) and stickleback (Gasterosteus aculeatus). Human LIPL contains a TSP sequence (residues 414-421: Phe-Ser-Trp-Ser-Asp-Trp-Trp-Ser) similar to the repeats found in thromobospondin 1 (TSP1) that mediates cell-to-cell and cell-to-matrix interactions (see Wolf et al, 1990). The first and second Trp residues in this sequence were retained for all vertebrate LIPL sequences examined which is consistent with in vitro studies of Beg and coworkers (1998) for synthetic LIPL peptides. Comparisons of the four basic amino acid clusters showed conservation for these sequences (human LIPL numbers used): cluster 1 (residues 287-312) retained Arg288, Lys292, Lys297, Arg304, Lys305 and Arg307 for all of the vertebrate LIPL sequences examined with the exception of Lys292, which was substituted by Arg for the fish sequences, and Arg304, substituted by Lys for opossum LIPL; cluster 2 (residues 315-332) retained Lys317, Arg319, Lys321, Arg322, Lys325, Lys330 and Arg332, with the exception of chicken LIPL (first Lys substituted by Arg) and the fish LIPL sequences examined for the second Lys, which was substituted by Arg (Danio rerio) or by Thr (Gasterosteus aculeatus); cluster 3 (residues 173-177) retained Lys173, Lys174 and Arg177 with the exception of the fish LIPL sequences for which the first Lys was substituted by His; and cluster 4 (residues 329-441) which retained Lys330, Arg332, Lys334,Lys440 and Lys441, with the exception of Lys330 which was substituted by Arg for mouse and chicken LIPL sequences and of Lys440, which was substituted by Gln for the fish LIPL sequences. Synthetic peptide heparin binding properties for these clusters (Beg et al, 1998) is consistent with these results with clusters 1, 3 and 2, showing the strongest binding in vitro, whereas cluster 4 did not bind to heparin, under the conditions used in their study.

One N-glycosylation site has been previously reported for human LIPL at 70Asn-71His-72Thr and (Kobayashi et al, 1994) and a second site predicted at 386Asn-387-Lys-388Thr (van Tilbeurgh et al, 1994). A comparative analysis of potential N-glycosylation sites for vertebrate LIPL (Table 3) has shown that there are 7 sites overall although only two of these have been predominantly retained for the 20 vertebrate LIPL sequences examined (designated as sites 2 and 4) (with the exception of stickleback LIPL which has lost site 2 but gained site 1 at 34Asn- 
35Thr-36Thr) (Table 3). It is apparent from the study by Kobayashi and coworkers (1994) of a human LIPL Asn70 variant that this $\mathrm{N}$-glycosylation site is essential for catalysis and secretion. A key role for the second predicted Nglycosylation site is also likely given the conservation of this site for all vertebrate LIPL sequences examined (Table 3). Other vascular neutral lipases contained four $\mathrm{N}$-glycosylation sites which play key roles and contribute to enzyme stability, secretion and catalytic activity: LIPC (hepatic lipase) (Wolle et al. 1993; Ben-Zeev et al. 1994) and LIPE (endothelial lipase) (Miller et al. 2004; Skropeta et al. 2007). A single N-glycosylation site was observed for horse LIPP at 45Asn-46Leu-47Thr which is consistent with a previous report (Bourne et al., 1994).

\section{Predicted Secondary and Tertiary Structures for Vertebrate LIPL}

Predicted secondary structures for vertebrate LIPL sequences were compared with the previously reported secondary structure for horse LIPP (Bourne et al., 1994) (Figure 1). $\alpha$-Helix and $\beta$-sheet structures for the vertebrate LIPL sequences were similar for several regions with the horse LIPP secondary structures. Consistent structures were predicted near key residues or functional domains including the $\beta$-sheet and $\alpha$-helix structures near the active site residues (human LIPL numbers used) Ser159, Asp 183 and His269; the 'lid' domain (residues 243-265); and the 'hinge' region (residues 317-330) which concludes with a $\beta$-sheet: Lys326-Met327-Tyr328-Leu329-Lys330. Figure 3 describes predicted tertiary structures for human, opossum (Monodelphis domestica) and frog (Xenopus tropicalis) LIPL protein sequences and shows significant similarities for these polypeptides with horse pancreatic lipase (LIPP) (Bourne et al., 1994). The three LIPL and LIPP domains were readily apparent, including the N-terminal 'lipase' domain with the active site triad residues buried under the 'lid' domain observed for horse LIPP. The 'lid' has been previously shown to contribute to the preference for triglyceride and phopholipid substrates of other vascular lipases (LIPC and LIPE) (Dugi et al., 1995; Kobayashi et al., 1996) and may play a major role in determining the preference for triglyceride rich lipoprotein LIPL substrates. A 'hinge' region was also observed for vertebrate LIPL proteins, separating the 'lipase' and 'plat' domains, with the latter having a 'sandwich-like' $\beta$-pleated sheet structure. The 'plat' domain for LIPC and LIPE has been shown to be essential for binding these enzymes to lipoprotein micelles and also contributes to preferences in lipoprotein binding (Wong et al, 1991; reviewed in Griffon et al, 2009). Biochemical studies have also shown that LIPL behaves as a dimer (Olivecrona \& Bengtsson-Olivecrona, 1983). In addition, a proprotein convertase proteolytic cleavage site was observed at the 'hinge' region (Arg319-X320Lys321-Arg322) (Figure 2), which may result in partially cleaved dimeric LIPL forms with reduced activities and unknown biochemical roles, similar to those observed for LIPE (Griffon et al, 2009). Comparisons of amino acid sequences studies for other vertebrate LIPL proteins suggest that these properties and key sequences are substantially retained for all of the sequences examined. 


\section{Gene Locations and Exonic Structures for Vertebrate LIPL Genes}

Table 1 summarizes the predicted locations for vertebrate $L I P L$ genes based upon BLAT interrogations of several vertebrate genomes using the reported sequences for human (Wion et al., 1987; Chuat et al., 1992), mouse (Zechner et al., 1991), rat (Brault et al., 1992; The MGC Project Team, 2004) and chicken (Cooper et al., 1992) and the predicted sequences for other vertebrate LIPL genes and the UC Santa Cruz genome browser (Kent et al. 2003). The predicted vertebrate LIPL genes were predominantly transcribed on the positive strand, with the exception of the marmoset, rat, dog, platypus, chicken and frog genes, which were transcribed on the negative strand. Figure 1 summarizes the predicted exonic start sites for human, mouse, rat, opossum, chicken, frog and stickleback $L I P L$ genes with each having 9 coding exons, in identical or similar positions to those predicted for the human LIPL gene (Wion et al., 1987; Chuat et al., 1992), with the exception of stickleback $L I P L$, which contained an additional exon encoding an extended C-terminal sequence.

Figure 4 shows the predicted structures of mRNAs for human and mouse $L I P L$ transcripts for the major isoform in each case (Theirry-Mieg \& Thierry-Mieg, 2006). The transcripts were 27-28.5 kbs in length with 9 introns present for these LIPL mRNA transcripts and in each case, an extended 3'-untranslated region (UTR) was observed. The human $L I P L$ genome sequence contained several predicted transcription factor binding sites (TFBS), a microRNA site (miR-29) located in the 3'-untranslated region and a CpG island (CpG112) which includes the 5'untranslated region of human $L I P L$ on chromosome 8 . This $\mathrm{CpG}$ island within the $L I P L$ gene promoter may play a role in maintaining a very high level of gene expression (4.5 times the average for human genes) (Theirry-Mieg \& Thierry-Mieg, 2006) which is similar to the $\mathrm{CpG}$ islands within housekeeping gene promoters expressed in most tissues (Saxonov et al., 2006). Of particular significance among the TFBS sites observed is the PPAR $\gamma$ (peroxisome proliferator-activated receptor- $\gamma$ ) site which participates in regulating cholesterol uptake and efflux from macrophages, promotes uptake of oxidized LDL and the subsequent differentiation of monocytes into foam cells (Merkel et al, 2002; Stein \& Stein, 2003; AshokKumar et al, 2010). In addition, an extensively studied LIPL genetic variant (Pro12Ala) is associated with lowered transcription of $P P A R \gamma 2$ and a decreased risk for type 2 diabetes in human populations (Nagy \& Szanto, 2005). The prediction of a microRNA (MiR-29) binding site within the 3 'untranslated region of human $L I P L$ is also potentially of major significance because small noncoding RNAs regulate mRNA and protein expression and have been implicated in regulating gene expression during embryonic development (Stephani \& Slack, 2008).

\section{Comparative Human and Mouse LIPL Tissue Expression}


Figure 5 presents 'heat maps' showing comparative gene expression for various human and mouse tissues obtained from GNF Expression Atlas Data using the U133A and GNF1H (human) and GNF1M (mouse) chips (http://genome.ucsc.edu; http://biogps.gnf.org) (Su et al, 2004). These data supported a broad and high level tissue expression for human and mouse $L I P L$, particularly for heart, skeletal muscle, adipose tissue and lung, which is consistent with previous reports for these genes (Levak-Frank et al, 1999; Mead et al, 2002). Other comparisons of human and mouse $L I P L$ tissue expression indicated significant species differences, with higher levels of gene expression observed in human placenta and nerve tissues but lower expression levels in human liver, kidney and ovary than for the corresponding mouse tissues. Overall however, human and mouse LIPL tissue expressions levels were $>4$ times the average level of gene expression which supports the key role played by this enzyme in lipid metabolism, especially in heart, skeletal muscle and adipose tissue (http://www.ncbi.nlm.nih.gov/IEB/Research/Acembly/) (Theirry-Mieg \& Thierry-Mieg, 2006).

\section{Phylogeny and Divergence of LIPL and Other Vertebrate Lipase Sequences}

A phylogenetic tree (Figure 6) was calculated by the progressive alignment of 20 vertebrate LIPL amino acid sequences with human and mouse LIPC and LIPE sequences which was 'rooted' with the Ciona intestinalis (sea squirt) lipase sequence (see Table 1). The phylogram showed clustering of the LIPL sequences into groups which were consistent with their evolutionary relatedness as well as groups for human and mouse LIPC and LIPE sequences, which were distinct from the sea squirt lipase sequence. These groups were significantly different from each other (with bootstrap values of $\sim 100 / 100$ ). It is apparent from this study of vertebrate LIPL genes and proteins that this is an ancient protein for which a proposed common ancestor for the LIPC, LIPG and LIPL neutral lipase genes may have predated the appearance of fish $>500$ million years ago (Donoghue \& Benton, 2007). This proposal is consistent with a previous report from Cohen (2003) which described predicted amino acid sequences for human and pufferfish (Takifugu rubripes) LIPE, LIPL and LIPC. Genetic distances for human, cow, mouse and rat LIPL, LIPG and LIPC sequences calculated from a mammalian common ancestor were as follows: $0.037 \pm 0.007$, $0.086 \pm 0.007$ and $0.125 \pm 0.011$, respectively, which suggest that mammalian LIPL sequences are diverging $\sim 2-3$ times more slowly than for LIPC and LIPE sequences. This is indicative of a conservative LIPL protein during mammalian evolution.

\section{Conclusions}

The results of the present study indicate that vertebrate $L I P L$ genes and encoded enzymes represent a distinct gene and enzyme family of neutral lipases which share key conserved sequences that have been reported for 
other neutral lipases previously studied (Datta et al., 1988; Cai et al., 1989; Bourne et al., 1994; Jaye et al., 1999; Hirata et al., 1999;). This enzyme has a unique property among the neutral lipases studied in hydrolyzing circulating chylomicrons and very low density lipoproteins (VLDL) and in facilitating receptor-mediated lipoprotein uptake into heart, muscle and adipose tissue of the body (Wion et al., 1987; Dichek et al., 1991; Benlian et al., 1996). LIPL is encoded by a single gene among the vertebrate genomes studied which is highly expressed in human and mouse tissues, particularly in heart, adipose tissue and skeletal muscle, and usually contained 9 coding exons. Predicted secondary structures and tertiary structures for vertebrate LIPL proteins showed a strong similarity with horse psancreatic lipase (LIPP) (Bourne et al., 1994). Three major structural domains were apparent for vertebrate LIPL, including the 'lipase' domain containing the catalytic triad residues; the 'lid' which covers the active site and may contribute to the substrate specificities of neutral lipases (Dugi et al., 1995; Kobayashi et al., 1996); and the 'plat' domain which contributes to lipoprotein binding (Wong et al., 1991). Phylogenetic studies using 20 vertebrate LIPL with human and mouse LIPC and LIPE sequences indicated that the LIPL gene has appeared early in vertebrate evolution, prior to the appearance of bony fish more that 500 million years ago, and is evolving 2-3 times more slowly that the other neutral lipase genes and proteins during mammalian evolution.

\section{Acknowledgements:}

This project was supported by NIH Grants P01 HL028972 and P51 RR013986. In addition, this investigation was conducted in facilities constructed with support from Research Facilities Improvement Program Grant Numbers 1 C06 RR13556, 1 C06 RR15456, 1 C06 RR017515. We also acknowledge the expert assistance of Dr Bharet Patel of Griffith University with the phylogeny studies.

\section{REFERENCES}

Ailhaud G (1990) Cellular and secreted lipoprotein lipase revisited. Clin Biochem 23: 343-347

Altschul F, Vyas V, Cornfield A, Goodin S, Ravikumar TS, Rubin EH, Gupta E (1997) Basic local alignment search tool. J Mol Biol 215: 403-410.

Ameis D, Kobayashi J, Davis RC, Ben-Zeev O, Malloy MJ, Kane JP, Lee G, Wong H, Havel RJ, Schotz MC (1991) Familial chylomicronemia (type I hyperlipoproteinemia) due to a single missense mutation in the lipoprotein lipase gene. J. Clin Invest 87:1165-1170

AshokKumar M, Subhashini NGV, Kanthimathi S, SaiBabu R, Ramesh A, Cherian KM, Emmanuel C (2010) Associations for lipoprotein lipase and peroxisome proliferator-activated receptor- $\gamma$ gene and coronary heart disease in an Indian population. Arch Med res 41: 19-25

Badaoui B., Serradilla J.M., Tomas A., Urrutia B., Ares J.L., Carrizosa J., Sanchez A., Jordana J., Amills M. (2007) Identification of two polymorphisms in the goat lipoprotein lipase gene and their association with milk production traits. J Dairy Sci 90:3012-3017 
Beg OU, Uddin M, Siddiqi (1998) Analysis of heparin-binding sites in human lipoprotein lipase using synthetic peptides. J prot Chem 17: 807-815

Benlian P, De Gennes JL, Foubert L, Zhang H, Gagne SE, Hayden M (1996) Premature atherosclerosis in patients with familial chylomicronemia caused by mutations in the lipoprotein lipase gene. N Engl J Med $335: 848-854$

Ben-Zeev, O, Stahnke G, Liu RC, Davis RC, Doolittle MH (1994) Lipoprotein lipase and hepatic lipase: the role of asparagines linked glycosylation in the expression of a functional enzyme. J Lipid Res 35: 1511-1522

Blain J.F, Aumont N, Theroux L, Dea D, Poirier J (2006) A polymorphism in lipoprotein lipase affects the severity of Alzheimer's disease pathophysiology. Eur. J. Neurosci. 24:1245-1251

Brault D, Noe L, Etienne J, Hamelin J, Raisonnier A, Souli A, Chuat J-C, Dugail I, Quignard-Boulange A, Lavau M, Galibert F (1992) Sequence of rat lipoprotein lipase-encoding cDNA. Gene 121:237-246

Brown RJ, Rader DJ (2007) Lipases as modulators of atherosclerosis in murine models. Curr. Drug Targets 8: 1307-1309.

Bourne Y., Martinez C., Kerfelec B., Lombardo D., Chapus C., Cambillau C (1994) Horse pancreatic lipase. The crystal structure refined at 2.3-A resolution. J. Mol. Biol. 238:709-732.

Bovine Genome Project (2008) http://hgsc.bcm.tmc.edu/projects/bovine

Cai SJ, Wong DM, Chen SH, Chan L (1989) Structure of the human hepatic triglyceride lipase gene. Biochem 28: 8966-8971

Casanovas A, Carrascal M, Abián J, Lópes-Tejero MD, Llobera M (2009) Lipoprotein lipase is nitrated in vivo after lipopolysaccharide challenge. Free Rad Biol Med 47: 1553-1560

Chen P, Jou YS, Fann CS, Chen JW, Wu SY, Pan WH (2005) Lipoprotein lipase gene is linked and associated with hypertension in Taiwan young-onset hypertension genetic study. J. Biomed. Sci. 12:651-658

Chimpanzee Sequencing and Analysis Consortium (2005) Initial sequence of the chimpanzee genome and comparison with the human genome. Nature 437: 69-87

Chuat J-C, Raisonnier A, Etienne J, Galibert F (1992) The lipoprotein lipase-encoding human gene: sequence from intron- 6 to intron-9 and presence in intron-7 of a 40-million-year-old Alu sequence. Gene 110:257-261

Cohen JC (2003) Endothelial lipase: direct evidence for a role in HDL metabolism. J Clin Invest 111: 1-3

Cole SA, Hixson JE (1995) Baboon lipoprotein lipase: cDNA sequence and variable tissue-specific expression of two transcripts. Gene 161:265-269

Cooper DA, Lu SC, Viswanath R, Freiman RN, Bensadoun A (1992) The structure and complete nucleotide sequence of the avian lipoprotein lipase gene. Biochim. Biophys. Acta 1129:166-171

Datta S, Luo CC, Li WH, VanTuinen P, Ledbetter DH, Brown MA, Chen SH, Liu S, Chan L (1988) Human hepatic lipase. Cloned cDNA sequence, restriction fragment length polymorphisms, chromosomal localization, and evolutionary relationships with lipoprotein lipase and pancreatic lipase. J Biol Chem 263:1107-1110.

Dichek HL, Fojo SS, Beg OU, Skarlatos SI, Brunzell JD, Cutler GB Jr, Brewer HB Jr (1991) Identification of two separate allelic mutations in the lipoprotein lipase gene of a patient with the familial hyperchylomicronemia syndrome. J Biol Chem 266:473-477.

Donoghue PCJ, Benton MJ (2007) Rocks and clocks: calibrating the tree of life using fossils and molecules. Trends Genet 22: 424-431. 
Dugi KA, Dichek HL, Santamarina-Fojo S (1995) Human hepatic and lipoprotein lipase: the loop covering the catalytic site mediates lipase substrate specificity. J. Biol. Chem. 270: 25396-25401.

Edwards WD, Daniels SW, Page RA, Volpe CP, Kille P, Sweeney GE, Cryer A (1993) Cloning and sequencing of a full length cDNA encoding ovine lipoprotein lipase. Biochim Biophys Acta 1172:167-170

Emmanuelsson O, Brunak S, von Heijne G, Nielson H (2007) Locating proteins in the cell using TargetP, SignalP and related tools. Nat Protocols 2: 953-971

Enerbaeck S, Semb H, Bengtsson-Olivecrona G, Carlsson P, Hermansson M-L, Olivecrona T, Bjursell G (1987) Molecular cloning and sequence analysis of cDNA encoding lipoprotein lipase of guinea pig. Gene 58:1-12

Faustinella F, Chang A, van Biervliet JP, Rosseneu M, Vinaimont N, Smith LC, Chen S-H, Chan L (1991) Catalytic triad residue mutation (Asp156-->Gly) causing familial lipoprotein lipase deficiency. Co-inheritance with a nonsense mutation (Ser447-->Ter) in a Turkish family. J Biol Chem 266:14418-14424

Felsenstein J (1985) Confidence limits on phylogenies: an approach using the bootstrap. Evolution 39:783-789

Ginzinger DG, Lewis MES, Ma Y, Jones BR, Liu G, Jones SD (1996) A mutation in the lipoprotein lipase gene is the molecular basis of chylomicronemia in a colony of domestic cats. J Clin Invest 97:1257-1266

Griffon N, Jin W, Petty DJ, Millar J, Badellino KO, Saven JG, Marchadier DH, Kempner ES, Billheimer J, Glick JM, Rader DJ (2009) Identification of the active form of endothelial lipase, a homodimer in a head to tail conformation. J Biol Chem 284: 23322-23330

Gouni I, OkaK, Etienne J, Chan L (1993) Endotoxin-induced hypertriglyceridemia is mediated by suppression of lipoprotein lipase at a post-transcriptional level. J Lipid Res 34:139-146

Guex N, Peitsch MC (1997) SWISS-MODEL and the Swiss-PdbViewer: An environment for comparative protein modelling. Electrophoresis 18: 2714-2723

Hall TA (1999) BioEdit: a user-friendly biological sequence alignment editor and analysis program for Windows 95/98/NT. Nucleic Acids Symp Ser 41:95-99

Harbitz I, Kristensen T, Kran S, Davies W (1992) Isolation and sequencing of porcine lipoprotein lipase cDNA and its use in multiallelic restriction fragment length polymorphism detection. Anim Genet 23:517-522

Hata A, Ridinger DN, Sutherland S, Emi M, Shuhua Z, Myers RL, Ren K, Cheng T, Inoue I, Wilson DE, Iverius P-H, Lalouel J-M (1993) Binding of lipoprotein lipase to heparin. J Biol Chem 268: 8447-8457

Hill JS, Davis RC, Yang D, Wen J, Philo JS, Poon PH, Phillips ML, Kempner ES, Wong H (1996) Human hepatic lipase subunit structure determination. J Biol Chem 271: 22931-22939

Hirata K, Dichek HL, Cioffi JA, Choi SY, Leeper NJ, Quintana L, Kronmal GS, Cooper AD, Quertermous T (1999) Cloning of a unique lipase from endothelial cells extends the lipase gene family. J Biol Chem 274: $14170-14175$

Horse Genome Project (2008) http://www.uky.edu/Ag/Horsemap/

Huang AQ, Hu YH, Zhan SY, Xu B, Pang ZC, Cao WH, Lu J, Qin Y, Lee LM (2006) Lipoprotein lipase gene S447X polymorphism modulates the relation between central obesity and serum lipids, a twin study. Int J Obes 30:1693-1701

Hubel CA, Roberts JM, Ferrell RE (1999) Association of pre-eclampsia with common coding sequence variations in the lipoprotein lipase gene. Clin Genet 56:289-296 
International Human Genome Sequencing Consortium (2001) Initial sequencing and analysis of the human genome. Nature 409: 860-921.

Jaye M, Lynch KJ, Krawiec J, Marchadier D, Maugeais C, Doan K, South V, Amin D, Perrone M, Rader DJ (1999) A novel endothelial-derived lipase that modulates HDL metabolism. Nat Genet 21:424-428

Jin W, Sun G-S, Marchadier D, Octtaviani E, Glick JM, Rader DJ. (2003) Endothelial cells secrete triglyceride lipase and phospholipase activities in response to cytokines as a result of endothelial lipase. Circ Res 92: 644650

Jin W., Fuki IV, Seidah NG, Benjannet S, Glick JM, Rader DJ. (2005) Proprotein convertases are responsible for proteolysis and inactivation of endothelial lipase. J. Biol. Chem. 280: 36551-36559

Jose Ibanez A, Peinado-Onsurbe J, Sanchez E, Cerda-Reverter JM, Prat F (2008) Lipoprotein lipase (LPL) is highly expressed and active in the ovary of European sea bass (Dicentrarchus labrax L.) during gonadal development. Comp Biochem Physiol Part A Mol Integr Physiol 150:347-354

Kent WJ, Sugnet CW, Furey TS (2003) The human genome browser at UCSC. Genome Res 12: 994-1006

Kimura M (1983) The neutral theory of molecular evolution. Cambridge University Press, Cambridge

Kobayashi J, Inadera H, Fujita Y, Talley G, Morisaki N, Yoshida S, Saito Y, Fojo SS, Brewer HB (1994) A naturally occurring mutation at the second base of codon asparagine 43 in the proposed N-linked glycosylation site of human lipoprotein lipase: in vivo evidence that asparagine 43 is essential for catalysis and secretion. Biochem Biophys Res Commun 205:506-515

Kobayashi J, Applebaum-Bowden D, Dugi KA, Brown DR, Kashyap VS, Parrott C, Duarte C, Maeda N, Santamarina-Fojo S. (1996) Analysis of protein structure-function in vivo. Adenovirus-mediated transfer of lipase lid mutants in hepatic lipase-deficient mice. J. Biol. Chem 271: 26296-262301.

Kobayashi Y, Nakajima T, Inoue I (2002) Molecular modeling of the dimeric structure of human lipoprotein lipase and functional studies of the carboxyl-terminal domain. Eur J Biochem 269:4701-10.

Kopp J, Schwede T (2004) The SWISS-MODEL Repository of annotated three-dimensional protein structure homology models. Nucleic Acids Res 32: D230-D234

Kosaka T, Yoshino J, Inui K, Wakabayashi T, Okushima K, Kobayashi T, Miyoshi H, Nakamura Y, Hayashi S, Shiraishi T, Watanabe M, Yamamoto T, Nakahara A, Katoh T (2006) Impact of lipoprotein lipase gene polymorphisms on ulcerative colitis. World J Gastroenterol 12:6325-6330

Levak-Frank S, Hofmann W, Weinstock PH, Radner H, Sattler W, Breslow J.L, Zechner R (1999) Induced mutant mouse lines that express lipoprotein lipase in cardiac muscle, but not in skeletal muscle and adipose tissue, have normal plasma triglyceride and high-density lipoprotein-cholesterol levels. Proc Natl Acad Sci USA 96:3165-3170

Ma K, Cilingiroglu M, Otvos JD, Ballantyne CM, Marian AJ, Chan L (2003) Endothelial lipase is a major genetic determinant for high-density lipoprotein concentration, structure and metabolism. Proc Natl Acad Sci USA 100: 2748-2753.

Martin GA, Busch SJ, Meredith GD, Cardin AD, Blankenship DT, Mao SJT, Rechtin AE, Woods CW, Racke MM, Schafer MP, Fitzgerald MC, Burke DM, Flanagan MA, Jackson RL (1988) Isolation and cDNA sequence of human postheparin plasma hepatic triglyceride lipase. J Biol Chem 263:10907-10914

Martinez J, Dugaiczyk LJ, Zielinski R, Dugaiczyk A (2001) Human genetic disorders, a phylogenetic perspective. J Mol Biol. 308:587-96 
McGuffin LJ, Bryson K, Jones DT (2000) The PSIPRED protein structure prediction server. Bioinformatics 16: $404-405$

Mead JR, Irvine SA, Ramji DP (2002) Lipoprotein lipase: structure, function, regulation and role in disease. J. Mol. Med. 80:753-769

Merkel M, Eckel RH, Goldberg IJ (2002) Lipoprotein lipase: genetics, lipid uptake, and regulation. J Lipid Res 43:1997-2006

Mikkelsen TS, Wakefield MJ, Aken B, Amemiya CT, Chang JL, Duke S, Garber M, Gentles AJ, Goodstadt L, Heger A, Jurka J, Kamal M, Mauceli E, Searle SMJ, Sharpe T, Baker ML, Batzer MA, Benos PV, Belov K, Clamp M, Cook A, Cuff J, Das R, Davidow L, Deakin JE, Fazzari MJ, Glass JL, Grabherr M, Greally JM, Gu W, Hore TA, Huttley GA, Kleber M, Jirtle RL, Koina E, Lee JT, Mahony S, Marra MA, Miller RD, Nicholls RD, Oda M, Papenfuss AT, Parra ZE, Pollock DD, Ray DA, Schein JE, Speed TP, Thompson K, VandeBerg JL, Wade CM, Walker JA, Waters PD, Webber C, Weidman JR, Xie X, Zody MC, Broad Institute Genome Sequencing Platform, Broad Institute Whole Genome Assembly Team, Marshall Graves JA, Ponting CP, Breen M, Samollow PB, Lander ES, Lindblad-Toh K (2007) Genome of the marsupial Monodelphis domestica reveals innovation in noncoding sequences. Nature 447:167-175

Miller GC, Long CJ, Bojilova ED, Marchadier D, Badellino KO, Blanchard N, Fuki IV, Glick JM, Rader DJ (2004) Role of N-linked glycosylation in the secretion and activity of endothelial lipase. J Lipid Res 45:20802087

Mouse Genome Sequencing Consortium (2002) Initial sequencing and comparative analysis of the mouse genome. Nature 420: 520-562.

Murthy V, Julien P, Gagné C (1996) Molecular pathobiology of the human lipoprotein lipase gene. Pharmacol Therapeut 70:101-135

Nagy L, Szanto A (2005) Roles for lipid-activated transcription factors in atherosclerosis. Mol Nutr Food Res 49:1072-1074

Oku H, Tokuda M, Okumura T, Umino T (2006) Effects of insulin, triiodothyronine and fat soluble vitamins on adipocyte differentiation and LPL gene expression in the stromal-vascular cells of red sea bream, Pagrus major. Comp Biochem Physiol B Biochem Mol Biol 144:326-333

Olivecrona T, Bengtsson-Olivecrona G (1987) Lipoprotein lipase from milk-the model enzyme in lipoprotein lipase research. In: Borensztajn, J. (Ed.), Lipoprotein Lipase. Evener, Chicago, pp. 15-58

Papassotiropoulos A, Wollmer MA, Tsolaki M, Brunner F, Molyva D, Lutjohann D, Nitsch RM, Hock C (2005) A cluster of cholesterol-related genes confers susceptibility for Alzheimer's disease. J Clin Psychiatry 66:940947

Prater CA, Plotkin J, Jaye D, Frazier WA (1991) The properdin-like type I repeats of human thrombospondin contain a cell attachment site. J Cell Biol 112: 1031-40

Radha V, Vimaleswaran KS, Ayyappa KA, Mohan V (2007) Association of lipoprotein lipase gene polymorphisms with obesity and type 2 diabetes in an Asian Indian population. Int J Obes 31:913-918

Raisonnier A, Etienne J, Arnault F, Brault D, Noe L, Chuat J-C, Galibert F (1995) Comparison of the cDNA and amino acid sequences of lipoprotein lipase in eight species. Comp Biochem Physiol B 111: 385-398

Rat Genome Sequencing Project Consortium. (2004) Genome sequence of the Brown Norway rat yields insights into mammalian evolution. Nature 428, 493-521.

Reymer PWA, Gagne E, Groenemeyer BE, Zhang H, Forsyth I, Jansen H, Seidell JC, Kromhout D, Lie KE, Kastelein JJ, Hayden MR (1995) A lipoprotein lipase mutation (Asn291Ser) is associated with reduced HDL cholesterol levels in premature atherosclerosis. Nat Genet 10:28-34 
Saere-Vila A, Calduch-Giner JA, Gomez-Requeni P, Medale F, Kaushik S, Perez-Sanchez J (2005) Molecular characterization of gilthead sea bream (Sparus aurata) lipoprotein lipase. Transcriptional regulation by season and nutritional condition in skeletal muscle and fat storage tissues. Comp Biochem Physiol B 142: 224-232

Saitou N, Nei M (1987) The neighbour-joining method: a new method for reconstructing phylogenetic trees. Mol Biol Evol 4:406-411

Saxonov S, Berg P, and Brutlag DL. (2006) A genome-wide analysis of CpG dinucleotides in the human genome distinguishes two distinct classes of promoters, Proc. Natl. Acad. Sci. USA 103 :1412-1417.

Senda M, Oka K, Brown WV, Qasba PK, Furuichi Y (1987) Molecular cloning and sequence of a cDNA coding for bovine lipoprotein lipase. Proc Natl Acad Sci USA 84:4369-4373

Sendak R A, Bensadoun A (1998) Identification of a heparin-binding domain in the distal carboxyl-terminal region of lipoprotein lipase by site-directed mutagenesis. J Lipid Res 39:1310-1315

Shimo-Nakanishi Y, Urabe T, Hattori N, Watanabe Y, Nagao T, Yokochi M, Hamamoto M, Mizuno Y (2001) Polymorphism of the lipoprotein lipase gene and risk of atherothrombotic cerebral infarction in the Japanese. Stroke 32:1481-1486

Skropeta D, Settasatian C, McMahon MR, Shearston K, Caiazza D, McGrath KC, Jin W, Rader DJ, Barter PJ, Rye KA (2007) N-Glycosylation regulates endothelial lipase-mediated phospholipid hydrolysis in apoE- and apoA-I-containing high density lipoproteins. J Lipid Res 48:2047-2057

Spence JD, Ban MR, Hegele RA (2003) Lipoprotein lipase (LPL) gene variation and progression of carotid artery plaque. Stroke 34:1176-1180

SteinY, Stein O (2003) Lipoprotein lipase and atherosclerosis. Atherosclerosis 170:1-9

Stefani G, Slack FJ (2008) Small non-coding RNAs in animal development. Nat Rev Mol Cell Biol 9: 219-30.

Stins MF, Sivaram P, Sasaki A, Goldberg IJ (1993) Specificity of lipoprotein lipase binding to endothelial cells. J Lipid Res 34: 1853-1861

Su AI, Wiltshire T, Batalov S, Lapp H, Ching KR, Block D, Zhang J, Soden R, Hayakawa M, Kreiman G, Cooke MP, Walker JR, Hogenesch JB (2004) A gene atlas of the human and mouse protein encoding transcriptomes. Proc Natl Acad Sci USA 101: 6062-6067

The MGC Project Team. (2004) The status, quality, and expansion of the NIH full-length cDNA project: the Mammalian Gene Collection (MGC). Genome Res. 14:2121-2127.

Thierry-Mieg D, Thierry-Mieg J (2006) AceView: A comprehensive cDNA-supported gene and transcripts annotation. Genome Biology 7, S12 http://www.ncbi.nlm.nih.gov/IEB/Research/Acembly/index.html?human

Tsutsumi K (2003) Lipoprotein lipase and atherosclerosis. Current Vascular Pharmacol 1: 11-17

Ukkola O, Salonen J, Kesaniemi YA (2005) Role of candidate genes in the lipid responses to intensified treatment in Type 2 diabetes. J. Endocrinol. Invest. 28:871-875

Van De Peer Y, de Wachter R (1994) TreeCon for Windows: a software package for the construction and drawing of evolutionary trees for the Microsoft Windows environment. Comput Appl Sci 10:569-575

van Tilbeurgh H, Roussel A, Lalouel J-M (1994) Lipoprotein lipase. Molecular model based on the pancreatic lipase X-ray structure: consequences for heparin binding and catalysis. J Biol Chem 269:4626-4633 
Walker JR, Davis T, Seitova A, Butler-Cole C, Weigelt J, Sundstrom M, Arrowsmith CH, Edwards AM, Bochkarev A, Dhe-Paganon S (2010) Protein data bank entry for human pancreatic lipase-related protein 1 (2PPL) http://www.rcsb.org/pdb/explore/explore.do?structureId=2PPL

Warren WC, Hillier LW, Marshall Graves JA, Birney E, Ponting CP, Grützner F, Belov K (2008) Genome analysis of the platypus reveals unique signatures of evolution. Nature. 453:175-83.

Weinstock PH, Bisgaier CL, Aalto-Setälä K, Radner H, Ramakrishnan R, Levak-Frank S, Essenburg AD, Zechner R, Breslow JL (1995) Severe hypertriglyceridemia, reduced high density lipoprotein, and neonatal death in lipoprotein lipase knockout mice. Mild hypertriglyceridemia with impaired very low density lipoprotein clearance in heterozygotes. J Clin Invest 96: 2555-2568.

Winkler F.K., D'Arcy A., Hunziker W. (1990) Structure of human pancreatic lipase. Nature 343:771-774.

Wion K.L, Kirchgessner T.G, Lusis A.J, Schotz MC, Lawn RM. (1987) Human lipoprotein lipase complementary DNA sequence. Science 235:1638-1641.

Wolf FW, Eddy RL, Shows TB, Dixit VM (1990) Structure and chromosomal localization of the human thrombospondin gene. Genomics 6: 685-91

Wolle J, Jansen H, Smith LC, Chan L (1993) Functional role of N-linked glycosylation in human hepatic lipase: asparagine-56 is important for both enzyme activity and secretion. J. Lipid Res 34: 2169-2175

Wong H, Davis RC, Nikazy J, Seebart KE, Schotz MC (1991) Domain exchange: characterization of a chimeric lipase of hepatic lipase and lipoprotein lipase. Proc. Natl. Acad. Sci. USA 88: 11290-11294.

Wong H, Hill JS, Davis RC, Nikazy J, Schotz MC (1997) A molecular biology-based approach to resolve the subunit orientation of lipoprotein lipase. Proc Natl Acad Sci USA 94: 5594-5598.

Xu E, Li W, Zhan L, Guan G, Wang X, Chen S, Shi Y (2008) Polymorphisms of the lipoprotein lipase gene are associated with atherosclerotic cerebral infarction in the Chinese. Neuroscience 155: 403-408

Zechner R, Newman TC, Steiner E, Breslow JL (1991) The structure of the mouse lipoprotein lipase gene: a B1 repetitive element is inserted into the $3^{\prime}$ untranslated region of the mRNA. Genomics 11:62-76

Zhang Q, Liu Y, Liu BW, Fan P, Cavanna J, Galton DJ (1998) Common genetic variants of lipoprotein lipase and apolipoproteins AI-CIII that relate to coronary artery disease: a study in Chinese and European subjects. Mol Genet Metab 64:177-183

Zhang C, Austin MA, Edwards KL, Farin FM, Li N, Hsu L, Srinouanprachanh SL, Williams MA (2006) Functional variants of the lipoprotein lipase gene and the risk of preeclampsia among non-Hispanic Caucasian women. Clin Genet 69:33-39

Zhao S-P, Tong Q-G, Xiao Z-J, Cheng Y-C, Zhou H-N, and Shai Nie S (2003) The lipoprotein lipase Ser447Ter mutation and risk of stroke in the Chinese Clin Chim Acta 330: 161-164 


\section{Figure 1: Amino Acid Sequence Alignments for Vertebrate Lipoprotein Lipase and Horse Pancreatic Lipase Sequences}

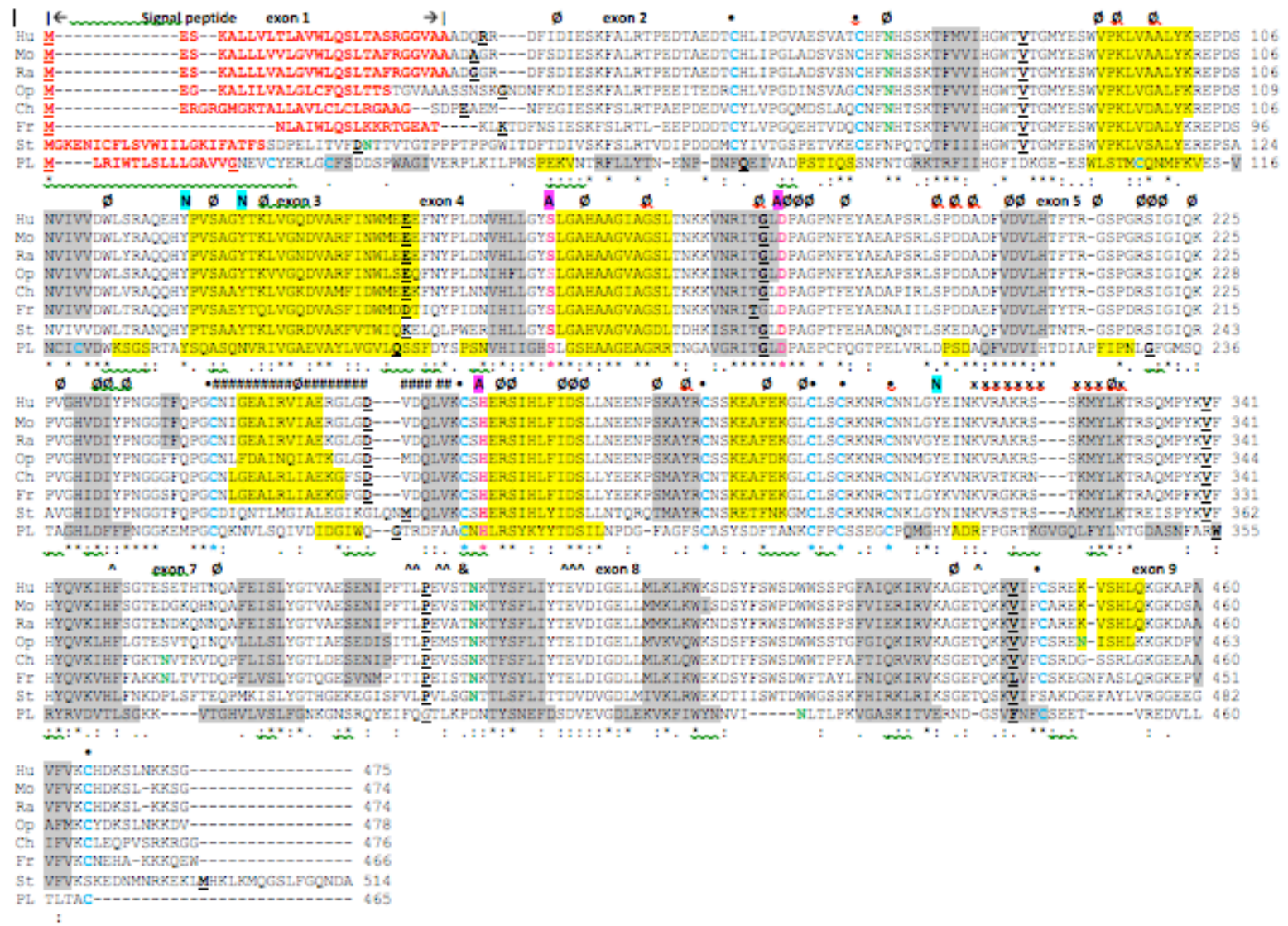

See Table 1 for sources of lipoprotein lipase (LIPL or LPL) and pancreatic lipase (LIPP) sequences: Hu-human LIPL; Momouse LIPL; Ra-rat LIPL; Op-opossum LIPL; Fr-frog LIPL; St-stickleback LIPL; PL-horse pancreatic lipase (LIPP); * shows identical residues for lipase subunits; : similar alternate residues; . dissimilar alternate residues; residues involved in $\mathrm{N}$-signal peptide formation are shown in red; human N-glycosylated and potential N-glycosylated Asn sites are in green bold; active site (A) triad residues Ser (S); Asp (D); and His (H) are in pink bold; predicted disulfide bond Cys residues are shown in blue bold $(\bullet)$; $\alpha$-helix for horse LIPP or predicted for vertebrate LIPL is in shaded yellow; $\beta$-sheet for horse LIPP or predicted for vertebrate LIPL is in shaded grey; bold underlined font shows residues corresponding to known or predicted exon start sites; exon numbers refer to human LIPL gene exons; \#\#\#\# refers to residues which correspond to the horse LIPP 'lid' region; $\mathbf{x x x x x}$ refers to the 'hinge' region for horse LIPP ^ refers to hydrophobic amino acids in the 'plat' domain which are located near to the active site triad in the LIPE dimer model reported by Griffon et al (2009); $\boldsymbol{\emptyset}$ refers to amino acid substitutions reported for human LIPL that result in activity loss and associated lipoproteinemia.

\section{Figure 2: Amino Acid Sequence Alignments for Predicted Heparin Binding Sites for Vertebrate Lipoprotein Lipases}

Basic amino acid and thrombospondin (TSP)-like clusters reported by Beg et al (1998) for human LIPL; K-lysine residue; Rarginine residue; $\mathrm{W}$-tryptophan residue; numbers refer to $\mathrm{C}$-terminal residue for each of the clusters examined for the 14 vertebrate LIPL sequences examined; for consensus sequences, $\mathrm{X}$ refers to any amino acid. 


\begin{tabular}{|c|c|c|c|c|c|c|c|c|c|c|}
\hline $\begin{array}{l}\text { Cluster } \\
\text { LIPL Consenous } \\
\text { Rrorretein Serpertage }\end{array}$ & $\begin{array}{l}3 \\
K K V N R\end{array}$ & & $\frac{1}{\text { YRCXSKBAEXKGLCLSCRKNRCNNX }}$ & & $\begin{array}{c}2 \\
\text { XNKVRXKRSSKNXLKTR } \\
\text { BxKB }\end{array}$ & & $\begin{array}{l}\text { TSP } \\
\text { EShSxinx }\end{array}$ & & $\stackrel{4}{\text { XRXRVKRGEIOKK }}$ & \\
\hline Human & KKWNR & 177 & YRCSSKRAPEKGLCLSCRKNRCNNL & 312 & INRVRAKRSSKYYLRTR & 332 & ESNSDWh & 421 & ORIRVKUGEIOKK & 441 \\
\hline Rhesus & KKVNR & 177 & YRCSSKEAFEKGLCLSCRKNRCNNL & 312 & INKVRAKRSSKVYLKTR & 332 & RSWSDWs & 421 & OKIRVKUGEIOKK & 441 \\
\hline Mouse & KKVNR & 177 & YRCNSKEAFEKGLCLSCRKNRCNNL & 312 & INKVRAKRSSKVYLKTR & 332 & BSWPDWW & 421 & ERIRVKMGEIOKK & 441 \\
\hline Rat & KKWNR & 177 & YRCNSKEAFEKGLCLSCRKNRCNNV & 312 & INKVRAKRSSKVYLKTR & 332 & ERWSDWS & 421 & EKIRVKUGEIOKK & 441 \\
\hline Dog & KKVNR & 173 & YRCNSKEAFEKGLCLSCRKNRCNNY & 308 & INKVRAKRGSKYYLKTR & 328 & ERWSDWW & 417 & OKIRVKMGEYOKK & 437 \\
\hline Opossum & KKINR & 180 & YRCSSKEAFDKGLCLSCKKNRCNNY & 315 & INKVRAKRSSKUYLKTR & 335 & ESWsDwh & 424 & OKIRVKAGEIOKK & 444 \\
\hline & KKVNR & 178 & YRCNSKEAFBKGLCLNCRKNRCNNL & 313 & VNKVRAKRSSKYYLKTR & 333 & ESNSGWW & 422 & OKVRVKNGEIOKK & 442 \\
\hline Chick. & KKVNR & 177 & YRCNTKEAFEKGLCLSCRKNRCNNL & 312 & VNRVRTKRNTKVYLKTR & 333 & BSWSDWE & 421 & ORVRVKSGEIOKK & 441 \\
\hline Frog & KKVNR & 167 & YRCNSKEAFEKGLCLSCRKNRCNTL & 302 & VNKVRGKRSTKVYLKTR & 323 & ESWSDFY & 411 & OKIRVKSGEFOKK & 431 \\
\hline zebres & HKVNR & 198 & FRCSSRDSFNKGMCLSCRKNACNRV & 331 & VNKIRTRRSSKNYMKTR & 352 & ISNP- WwN & 438 & RKIRIKSGEIOSK & 459 \\
\hline Stickleback & HKISR & 197 & YRCNSRETENKGMCLSCRKNRCNKL. & 333 & INKVRSFRSAKNYLKTR & 354 & ISNTDWW & 441 & RKIRIKSGEIOSK & 462 \\
\hline
\end{tabular}

Figure 3: Tertiary Structure for Horse Lipoprotein Lipase and Predicted Tertiary Structures for Human, Opossum and Frog Lipoprotein Lipases

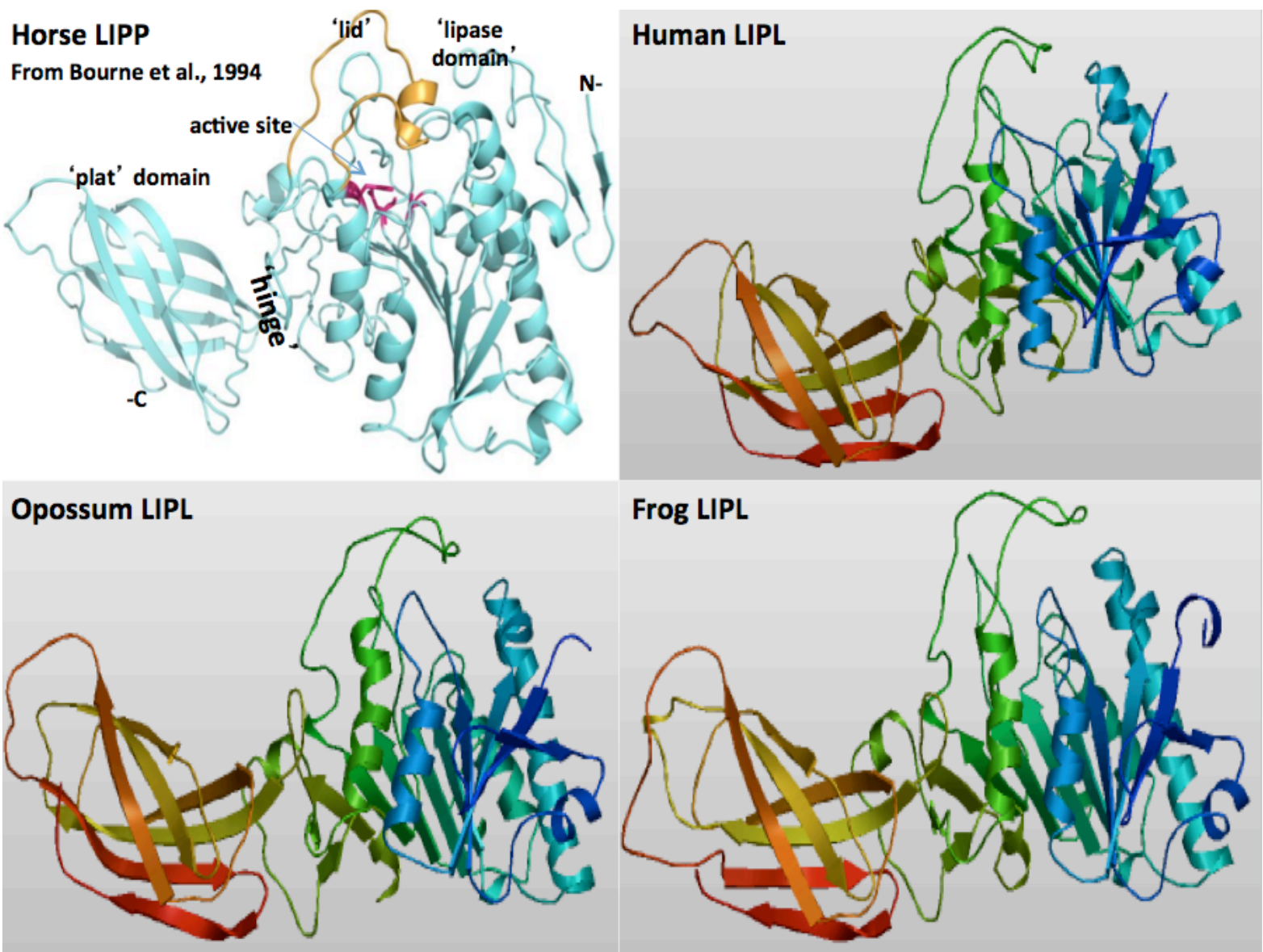

The structure for horse pancreatic lipase (LIPP) is taken from Bourne et al, 1994; predicted human, opossum and frog lipoprotein lipase (LIPL) tertiary structures were obtained using SWISS MODEL methods; the rainbow color code describes the tertiary structures from the $\mathrm{N}$ - (blue) to C-termini (red color) for human, opossum and zebrafish LIPL; the horse LIPP tertiary structure shows the N- and C-termini, the 'lipase', 'lid' (in yellow) and 'plat' domains which are separated by a 'hinge' region; and the active site triad residues for horse LIPP which are shown in red.

\section{Figure 4: Gene Structures and Major Splicing Variant for the Human and Mouse Lipoprotein Lipase} (LIPL) Genes.

Derived from the AceView website http://www.ncbi.nlm.nih.gov/IEB/Research/Acembly/ (Thierry-Mieg and ThierryMieg,2006); mature isoform variants (a) are shown with capped 5'- and 3'- ends for the predicted mRNA sequences; NM refers to the NCBI reference sequence; exons are in pink; the directions for transcription are shown as 5' $\rightarrow$ 3'; blue triangles show predicted $\mathrm{CpG}$ island sites at or near the 5'untranslated regions of the gene; the blue square shows a predicted microRNA binding site (miR29) observed at or near the human LIPL 3'untranslated region; sizes of mRNA sequences are 
shown in kilobases (kb); predicted transcription factor binding sites (TFBS) for human LIPL are shown: FoxJ2-Foxhead J2 protein; Zic1-Zinc finger protein Zic1; E2F-transcription factor E2F2; HNF4 hepatocyte nuclear factor; ER-estrogen receptor DNA binding; PPARG-peroxisome proliferator-activated receptor $\gamma$.

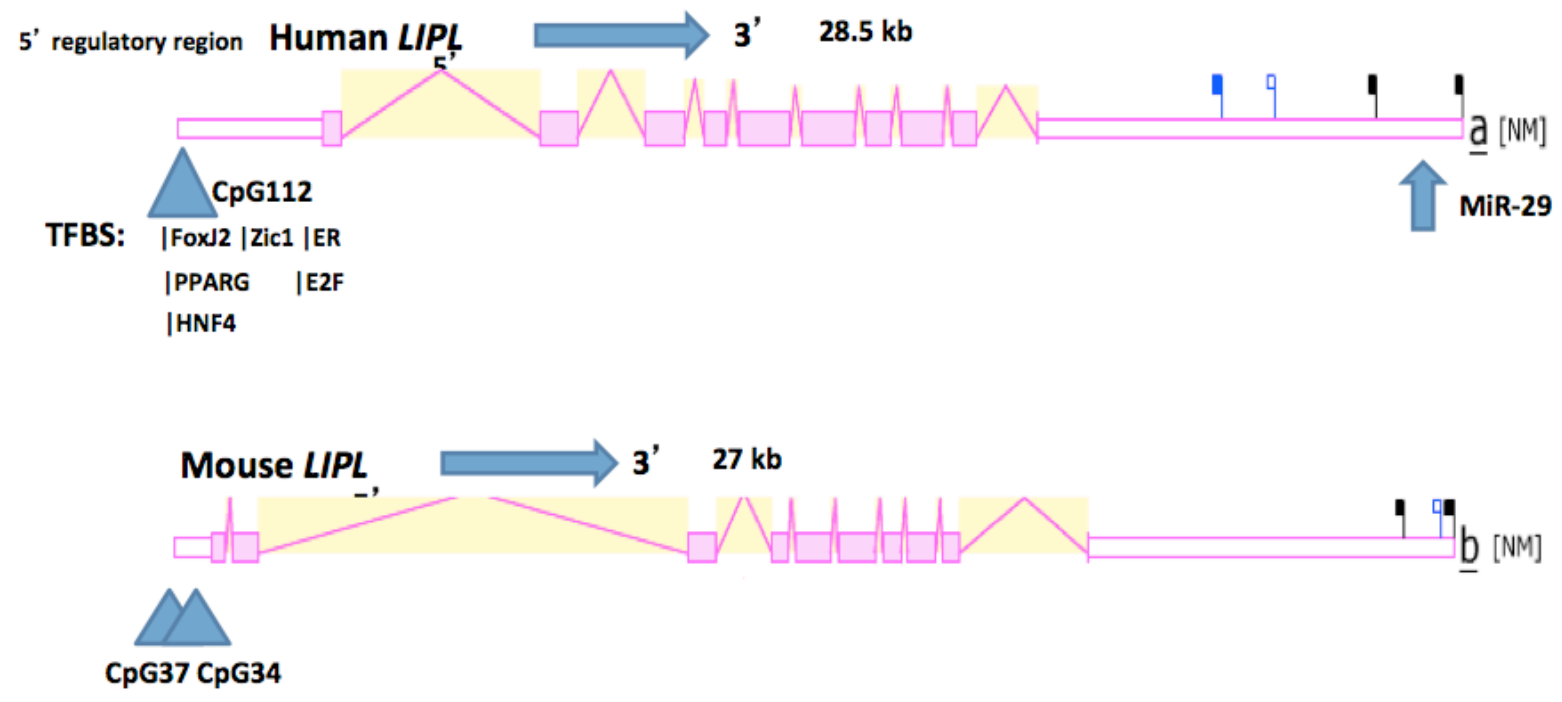

Figure 5: Comparative Tissue Expression for Human and Mouse Lipoprotein Lipase Genes $(L I P L)$

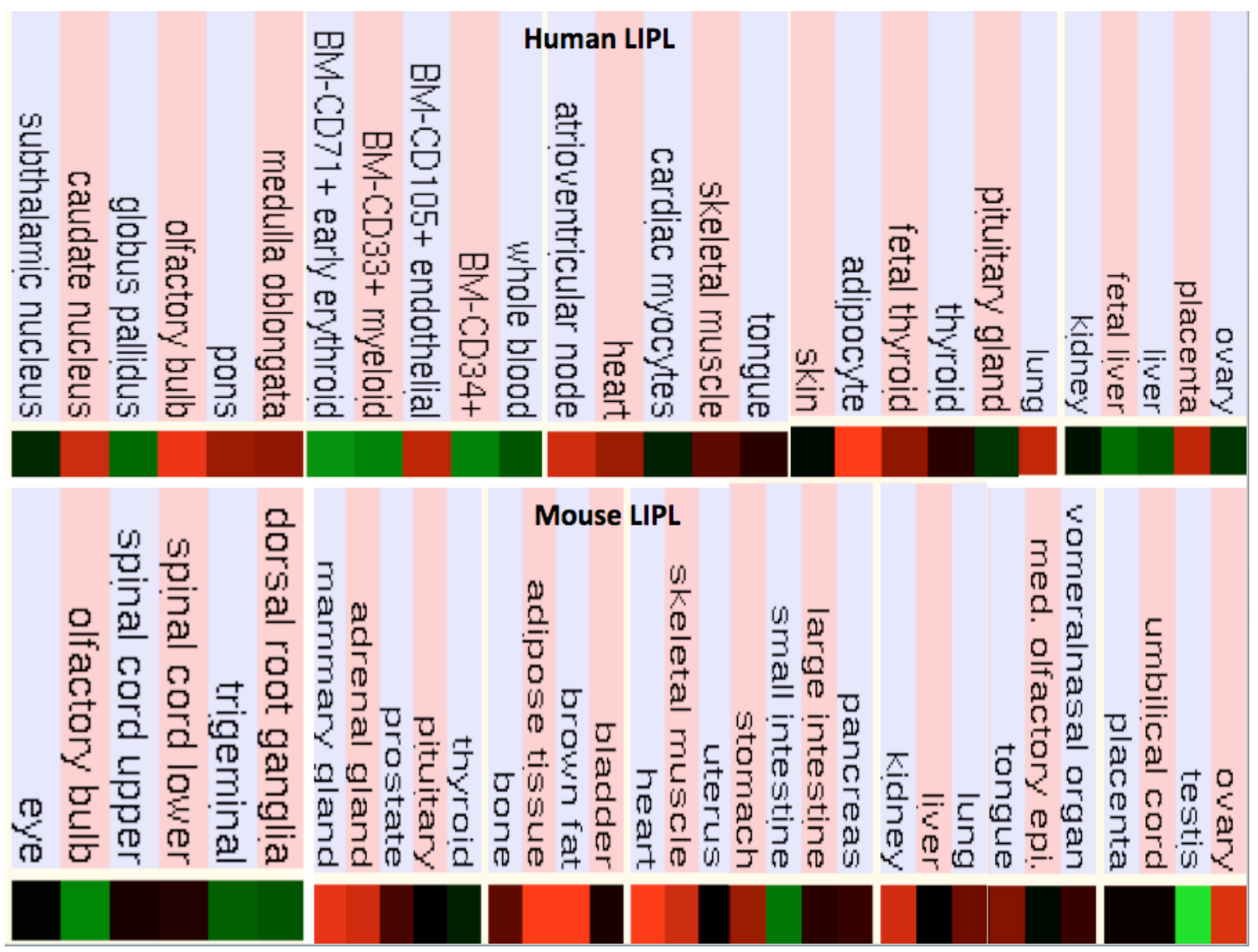

Expression 'heat maps' (GNF Expression Atlas 2 data) (http://biogps.gnf.org) (Su et al, 2004) were examined for comparative gene expression levels among human and mouse tissues for LIPL genes showing high (red); intermediate (black); and low (green) expression levels. Derived from human and mouse genome browsers (http://genome.ucsc.edu) (Kent et al. 2003). 
Figure 6: Phylogenetic Tree of Vertebrate Lipoprotein Lipase (LIPL) and Human and Mouse Hepatic Lipase (LIPC) and Endothelial Lipase (LIPE) Amino Acid Sequences

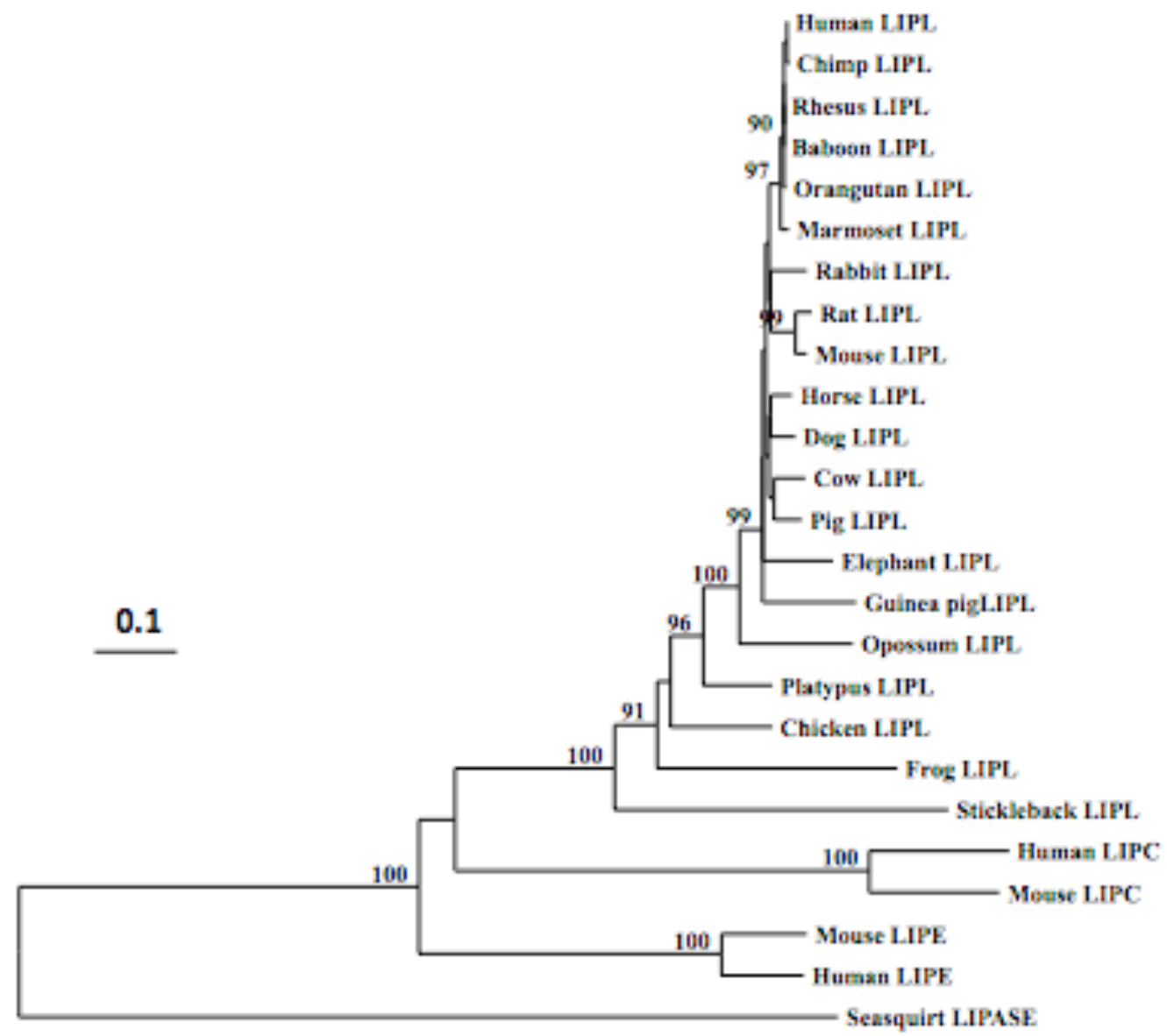

The tree is labeled with the lipase name and the name of the animal and is 'rooted' with the seasquirt lipase sequence (Ciona intestinalis). Note the 3 major clusters corresponding to the LIPL, LIPG and LIPC neutral lipase gene families, encoding lipoprotein lipase (LIPL), endothelial lipase (LIPE) and hepatic lipase (LIPC), respectively. A genetic distance scale is shown. The number of times a clade (sequences common to a node or branch) occurred in the bootstrap replicates are shown. Only replicate values of 90 or more which are highly significant are shown with 100 bootstrap replicates performed in each case.

Table 1: Vertebrate lipoprotein lipase (LIPL), seasquirt (Ciona intestinalis) lipase, human and mouse hepatic lipase $(L I P C)$ and endothelial lipase $(L I P G)$ and horse pancreatic lipase $(L I P P)$ genes and proteins RefSeq: the reference amino acid sequence; ${ }^{1 / 3}$ predicted Ensembl amino acid sequence; ${ }^{2}$ not available; ${ }^{4}$ Contig refers to a DNA scaffold for sequencing analyses; GenBank IDs are derived NCBI http://www.ncbi.nlm.nih.gov/genbank/; Ensembl ID was derived from Ensembl genome database http://www.ensembl.org; UNIPROT refers to UniprotKB/Swiss-Prot IDs for individual acid lipases (see http://kr.expasy.org); bps refers to base pairs of nucleotide sequences; $\mathrm{pI}$ refers to theoretical isoelectric points; the number of coding exons are listed. 


\begin{tabular}{|c|c|c|c|c|c|c|c|c|c|c|c|}
\hline Gene $U P P_{1}$ & & 'Ensembl (predicted) & & ID & acids & botation & (strand) & bps & & MW & (Cleavage site) \\
\hline Heman & Homo sopiens & NM_000237.2 & BC011353 & po5858 & 475 & $8: 19,841,232-19,864,008$ & 9 (twe) & $22, m$ & 84 & 53,163 & 1.27 [AA-AO] \\
\hline Chimpanzee & Pan trogiodytes & $X_{-} 001149904.1$ & $x$ & ${ }^{2}$ & 475 & $8: 16,183,708-16,206,551$ & $9($ twe) & 22,844 & 8.5 & 53,162 & 1-27 [AA-AO] \\
\hline Orangutan & Pango obelï & ' & ${ }^{2}$ & $x$ & 475 & $8: 19,482,810-19,505,529$ & $9($ twe $)$ & 22,720 & 85 & 53,133 & $1-27[A-A-A O]$ \\
\hline Rhesas & Macoca musiatto & 'ENSMMMUTO000000655.8 & $A f=03770$ & CQ5NMTO & 475 & $8: 19,847,146-19,860,974$ & 9 (twe) & 13,829 & 8.5 & 53,146 & 1-20 [TA-SR] \\
\hline Baboon & Popio anubis & NP_C01106082.1 & U18091 & P45050 & 475 & ${ }^{2}$ & 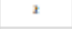 & $x$ & 8.5 & 53,146 & $1-20$ [TA-SR] \\
\hline Narmoset & Colletrix jacthos & , & ${ }^{x}$ & $x$ & 475 & Contie $4830-148,445-170,321$ & 9 (-ve) & 21.877 & 8.5 & 53,165 & $1-27[D A-A D]$ \\
\hline Nouse & Mus muscuíus & NM_0008509.2 & 86003305 & P11152 & 474 & $8: 71,404,552-71,426,282$ & $9(+\infty e)$ & 21,631 & 80 & 53,109 & 1-27 [AA-AO] \\
\hline Rat & Rattus norvegicus & NP_036730.1 & вс081836 & 006000 & 474 & $16: 22,536,120-22,556,716$ & 9 (-ve) & 20,597 & 8.4 & 53,082 & 1-27 [AA-AO] \\
\hline Guinea Pis & Cavis parcellos & ENSCPOTOOOOOOOTOSB & 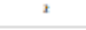 & P11153 & 475 & $1.57,048,993-57,068,443$ & $9(+$ tee) & 19,451 & 8.8 & 53,522 & $1-27[A-A-A K]$ \\
\hline Horse & Eques caballes & ${ }^{\prime} \theta_{-} 001480627.1$ & ${ }^{x}$ & $x$ & 468 & $2 \times 49,071,398-49,090,148$ & $9(+v e)$ & 18,751 & 90 & 52,467 & 1-21 [AA-DR] \\
\hline Cow & Bas towns & NP_Co1058588.1 & 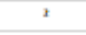 & ${ }^{x}$ & 478 & $8: 70,187,336-70,209,826$ & $9($ twe) & 22,491 & 88 & 53,378 & 1-23 [RG-GL] \\
\hline Dog & Conisfamiaris & $x 0_{-} 534586.2$ & $x$ & $x$ & 471 & $25 * 40,075,103 \cdot 40,095,543$ & 9 (-ve) & 20,441 & 85 & 52,559 & 1-21 [AA-AQ] \\
\hline Rabbit & Aryctologus cuniculos & NM_001177330.1 & FM29312 & $x$ & 474 & $15 \times, 554,425-4,578,617$ & $9(+v e)$ & 24,193 & 8.2 & 52,977 & 1-20 [TA-SR] \\
\hline Pig & Sus scroso & 'ENSSSCT00000010522 & AK344311 & P11151 & 478 & $14: 3,826,571-3,852,602$ & $9($ twe $)$ & 26,032 & 8.6 & 53,498 & 1-26 [LA-TA] \\
\hline Elephant & Larodonts afficans & ENSLAFTOO000005541 & $x$ & $x$ & 472 & $22: 17,198,146-17,219,228$ & 9 (twe) & 21,083 & 90 & 52,937 & 1-20 [PA-SH] \\
\hline Opossum & Monodeloghis domestica & Xo_001381955.1 & $x$ & $x$ & 478 & $1590,795,573-580,818,319$ & $9(+x e)$ & 22,747 & 8.6 & 53,362 & $1-21$ [TS-TG] \\
\hline Platypes & Orsitharhymchus anatinus & 'ENSOANTOOO00009473 & $x$ & $x$ & 476 & $5,4,223,188-4,247,644$ & 9 (-ve) & 24,457 & 8.4 & 53,558 & $1-26$ [AA-SO] \\
\hline Chicken & Gollos goilus & NM_205282 & AB016987 & P11612 & 475 & $2: 53,400,437-53,408,327$ & 9 (-ve) & 78991 & 85 & 53,635 & 1-25 [AG-SD] \\
\hline frog & Xenopess trapicaîs & 'ENSXETTO0000056503 & $x$ & ${ }^{2}$ & 466 & $4 \times 79: 338,410-419,025$ & $9(-$ we $)$ & 80,616 & 8.2 & 53,153 & 1-18 [AT-KL] \\
\hline Stickleback & Gosterastews oculeotus & 'ENSGACT00000015067 & $x$ & $x$ & 514 & VIII: $14,407,768-14,412,555$ & $10(-v e)$ & 4,788 & 8.2 & 58,052 & 1-23 [F5-SD] \\
\hline Sea squirt UPASE & Chono intestimalis & 'ENSCINTDOCOCOOC9034 & $x$ & $x$ & 460 & $07 q 1,1<8,429-1,153,888$ & 11 (-ve) & 5,460 & 457 & 51,184 & 1-18 [NC-DT] \\
\hline Human $L A P G$ & Homo sapiens & NM_006033.2 & $8 C 060825$ & arrs $\times 9$ & 500 & $18: 45,342,677-45,367,216$ & 10 (twe) & 24,540 & 8.1 & 56,795 & 1-20 [AG-SP] \\
\hline Mouse Linc & Mos muscuilus & NM_010720.3 & BC020991 & QOWVGS & 500 & $18 \cdot 75,102,995 \cdot 75,120,628$ & $10(-$ ve) & 17,633 & 8.79 & 56,629 & 1-20 [AG-SI] \\
\hline Heman $L P C$ & Homo sapiens & NM_000236.2 & BC146659 & P11150 & 499 & $15: 56,511,524-56,648,315$ & $9($ twe $)$ & 135,792 & 9.22 & 55,914 & $1-24$ [16-OS] \\
\hline Mouse LAPC & Mus muscuilus & NM_008280.2 & BC021841 & $P 27656$ & 510 & $9: 70,545,935-70,782,615$ & 9 (-ve) & 135,681 & 8.34 & 57,389 & $1-22$ [AC-GQ] \\
\hline Horse LPP & Equess caballus & NM_Co1163949 & $\times 56218$ & P29183 & 465 & $1: 15,534,773-15,551,621$ & $12(-\mathrm{ve})$ & 16849 & 55 & 54,435 & 1-16 [NG-NE] \\
\hline
\end{tabular}

Table 2: Percentage identities for vertebrate lipoprotein lipase (LIPL), human and mouse hepatic lipase (LIPC) and endothelial lipase (LIPE), horse pancreatic lipase (LIPP) and seasquirt lipase amino acid sequences

\begin{tabular}{|c|c|c|c|c|c|c|c|c|c|c|c|c|c|c|c|c|}
\hline Lipase Gene & Heman & Rhesus & Mouse & Rat & Horse & Cow & Opossum & Chicken & freg & Stickleback & Heman & Mouse & Heman & Mouse & Horse & Seasquirt \\
\hline & UPL & UPL & upt & UPt & UPL & UPt & UPL & UPL & UPL & UPt & UPC & UPC & UPE & UPE & UPp & UPASE \\
\hline Herman UPL & 100 & 99 & 92 & 91 & 94 & 92 & 81 & $n$ & $n$ & 58 & 41 & 4 & 44 & 45 & 24 & 25 \\
\hline Rhesus LPL & 99 & 100 & 92 & 92 & 94 & 92 & 82 & $n$ & $n$ & 58 & 43 & 44 & 44 & 44 & 24 & 25 \\
\hline Nouse UPL & 92 & 92 & 100 & 96 & 91 & 89 & 50 & 71 & 71 & 57 & 42 & 43 & 45 & 43 & 25 & 25 \\
\hline Rat LIPL & 91 & 92 & 96 & 100 & 91 & 89 & 81 & $n$ & $n$ & 58 & 42 & 43 & 45 & 45 & 24 & 24 \\
\hline Horse UPL & 94 & 94 & 91 & 91 & 100 & 91 & 81 & 73 & $n$ & 59 & 42 & 43 & 45 & 46 & 24 & 26 \\
\hline Cow LIP. & 92 & 92 & 80 & 80 & 91 & 100 & 50 & $n$ & 69 & 58 & 41 & 41 & 44 & 45 & 24 & 26 \\
\hline Opossum LPL & 81 & 82 & 50 & 81 & 81 & 50 & 100 & 70 & 70 & 55 & 39 & 41 & 43 & 44 & 23 & 25 \\
\hline Chicken UPL & $n$ & $n$ & $n$ & $n$ & 73 & $n$ & 70 & 100 & 75 & 60 & 42 & 40 & 49 & 46 & 25 & 24 \\
\hline Frog uph & $n$ & $n$ & $n$ & $n$ & $n$ & 69 & 70 & 75 & 100 & 60 & 40 & 41 & 46 & 45 & 25 & 25 \\
\hline Stickleback UPL & 58 & 58 & 57 & 58 & 59 & 58 & 55 & 60 & 60 & 100 & 35 & 33 & 39 & 39 & 25 & 21 \\
\hline Heman UPC & 41 & 43 & 42 & 42 & 42 & 41 & 39 & 42 & 40 & 36 & 100 & 74 & 38 & 37 & 25 & 25 \\
\hline Mouse UPC & 4 & 44 & 43 & 43 & 43 & 41 & 41 & 40 & 41 & 33 & 74 & 100 & 42 & 40 & 29 & 25 \\
\hline Heaman UPE & 44 & 44 & 45 & 45 & 45 & 44 & 43 & 49 & 46 & 39 & 38 & 42 & 100 & 50 & 25 & 25 \\
\hline Mouse UPE & 45 & 44 & 43 & 45 & 45 & 45 & 44 & 45 & 45 & 39 & 37 & 40 & 50 & 100 & 26 & 25 \\
\hline Horse UPp & 24 & 24 & 25 & 24 & 26 & 24 & 23 & 25 & 25 & 25 & 25 & 29 & 25 & 26 & 100 & 35 \\
\hline Sea squirt UPASE & 25 & 25 & 25 & 20 & 26 & 26 & 25 & 24 & 25 & 23 & 21 & 25 & 25 & 25 & 35 & 100 \\
\hline
\end{tabular}

Numbers show the percentage of amino acid sequence identities. Numbers in bold show higher sequence identities for lipases from the same gene family. LIPL, LIPC, LIPE and LIPP refer to lipoprotein lipase, hepatic lipase, endothelial lipase and pancreatic lipase amino acid sequences, respectively.

\section{Table 3: Predicted N-glycosylation sites for vertebrate lipoprotein lipases}

Numbers refer to amino acids in the acid sequences, including $\mathrm{N}$-asparagine; K-lysine; I-isoleucine; H-histidine; S-serine; Tthreonine; Q-glutamine; D-aspartate; Y-tyrosine; and V-valine. Note that there are 7 potential sites identified, including 2 sites for human LIPL (sites 2 and 4) (see Kobayashi et al, 1994; van Tilbeurgh et al, 1994). N-glycosylation sites were identified using the NetNGlyc 1.0 web server (http://www.cbs.dtu.dk/services/NetNGlyc/). 


\begin{tabular}{|c|c|c|c|c|c|c|c|c|c|}
\hline Vertebrate & Species & Site 1 & Site 2 & Site 3 & Site 4 & Site 5 & Site 6 & Site 7 & No of \\
\hline & & & & & & & & & Sites \\
\hline Heman & Homo sapiens & & TONHS & & $385 \mathrm{NKT}$ & & & & 2 \\
\hline Chimpanzee & Pan trogiodytes & & rovis & & $386 \mathrm{NKT}$ & & & & 2 \\
\hline Orangutan & Pango abeli & & rowks & & $365 \mathrm{NKT}$ & & & & 2 \\
\hline Rhesus & Mocact muiste & & rovis & & $386 \mathrm{NKT}$ & & & & 2 \\
\hline Baboon & Popio mubis & & TONHS & & $385 \mathrm{NKT}$ & & & & 2 \\
\hline Marmaset & Colvehrix jocthus & & rONHS & & $386 \mathrm{NKT}$ & & & & 2 \\
\hline Mouse & Mus musculus & & rowhs & & $365 \mathrm{NKT}$ & & & & 2 \\
\hline Rat & Rattus norwegicus & & TONHS & & $366 \mathrm{NKT}$ & 411NDS & & & 3 \\
\hline Guinea Pig & Covis parcellus & & rowhs & & $365 \mathrm{NNT}$ & & & & 2 \\
\hline Horse & Equus caballus & & 63Nas & & $379 \mathrm{NKT}$ & & & & 2 \\
\hline Cow & Bas towns & & 73NHS & & $369 \mathrm{NKT}$ & & & & 2 \\
\hline Dog & Canis familaris & & $66 \mathrm{NHT}$ & & $382 \mathrm{NKT}$ & & & & 2 \\
\hline Rabbit & Oryctologus cuniculos & & $69 \mathrm{NH} 5$ & & $385 \mathrm{NKT}$ & & & 471NKS & 3 \\
\hline Pig & Sus scrofo & & T3NHS & & 359NKT & & & & 2 \\
\hline Elephant & Larodonte afficang & & raNYS & & $385 \mathrm{NKT}$ & & & & 2 \\
\hline Opessum & Monodelyhis domestico & & $73 \mathrm{NHS}$ & & $360 \mathrm{NKT}$ & & $452 \mathrm{NIS}$ & & 3 \\
\hline Platypus & Orvitharhynchus anatinus & & 71NKT & & $387 \mathrm{NKT}$ & & & & 2 \\
\hline Chicken & Galws gailus & & roNhT & $354 \mathrm{NVT}$ & $385 \mathrm{NKT}$ & & & & 3 \\
\hline freg & Xenopus tropicalis & & 60NKT & $344 \mathrm{NLT}$ & $376 \mathrm{NKT}$ & & & & 3 \\
\hline Stickleback & Gosterastews aculeotus & $34 \mathrm{NTT}$ & & & $407 \mathrm{NT}$ & & & & 2 \\
\hline
\end{tabular}

